\title{
Effects of Isoproterenol, d1-Propranolol and d-Propranolol on the A-V Transmission and the A-V Nodal Transmembrane Action Potential
}

\author{
Shuhuang JEN (Shokoh NIN), M.D.
}

\section{SUMMARY}

The A-V nodal transmembrane action potential was recorded along with contiguous bipolar electrograms from the right atrium and ventricle in 61 isolated rabbit hearts driven from a point near the S-A node at a constant frequency.

Both dl- and d-propranolol prolonged the atrioventricular conduction time equally and this prolongation occurred not only in the anterior half of the A-V node but also in the ventricular conduction system. Isoproterenol shortened the atrioventricular conduction time. This shortening occurred mostly in the anterior half of the A-V node, and it was antagonized by $\mathrm{dl}-$ propranolol but not by d-propranolol.

These findings suggest the following: (i) the negative dromotropic action of $\beta$-adrenergic blocking agents is mainly due to non-specific mechanisms in the isolated heart where catecholamines are insufficient, while in the sympathomimetic amine excess (isoproterenol administration) heart it is mainly due to $\beta$-blocking mechanisms: (ii) the dromotropic action mediated by $\beta$-adrenergic receptors occurs mostly in the anterior half of the A-V node.

The second degree A-V block induced by either dl- or d-propranolol occurred between $\mathrm{AN}$ and $\mathrm{N}$ layer of the $\mathrm{A}-\mathrm{V}$ node, and it always began with the Wenckebach phenomenon.

The depolarization phase of the A-V nodal transmembrane action potential was shortened by isoproterenol, but prolonged by dl- and dpropranolol. These changes tended to be more marked in AN and $N$ rather than NH layer. Above findings were considered to correspond to the dromotropic actions induced by these drugs.

The slope of a slow diastolic depolarization recognized in only one A-V nodal fiber was increased by isoproterenol, but decreased by dl-propranolol.

\section{Additional Indexing Words:}

$\beta$-Adrenergic receptors Dromotropic actions $\beta$-Adrenergic stimulating and blocking actions Non-specific actions of $\beta$-blockers $A N, N$, NH layer

\footnotetext{
HLQUIST $^{11}$ classified adrenergic receptors into 2 types, i.e., $\alpha$ and $\beta$ receptors. It is widely believed that the latter plays an important role in 
cardiac function. Because the A-V node has been shown to have a great number of catecholamine-containing neurones, ${ }^{2}{ }^{2}$ it can be anticipated that the $\mathrm{A}-\mathrm{V}$ nodal function is closely related to $\beta$-adrenergic receptors. Therefore, there exist some studies on the relationship between $\beta$-adrenergic receptors and the $\mathrm{A}-\mathrm{V}$ transmission. However, the electrophysiological finding in the $\mathrm{A}-\mathrm{V}$ node related to $\beta$-adrenergic receptors has been left unsolved since the A-V nodal transmembrane action potential was not recorded in these studies. Accordingly, in the present experiment, the dromotropic actions of $\beta$-adrenergic stimulating and blocking agents were studied by means of recording the A-V nodal transmembrane action potential from the isolated rabbit heart.

The present study obtained findings on the following: (i) The region which is most related to $\beta$-adrenergic receptors as respects the dromotropic action; (ii) The possibility of dromotropic action of $\beta$-adrenergic blocking agents as due to $\beta$-adrenergic blocking mechanisms or non-specific mechanisms; (iii) The mode of the second degree $\mathrm{A}-\mathrm{V}$ block induced by $\beta$-adrenergic blocking agents; (iv) The effects of isoproterenol, dl- and d-propranolol on the A-V nodal transmembrane action potential, and their relationship to the A-V transmission.

\section{Methods}

Sixty-one rabbits weighing 2.5 to $3.0 \mathrm{Kg}$ were used in experiments. Each rabbit was anesthetized intravenously by pentobarbital sodium and its entire heart was excised. The isolated heart was constantly perfused through the aorta with fully oxygenated Ringer's solution at $35^{\circ} \mathrm{C}$ using the Langendorff's technique. After the septal surface of the right atrium and ventricle was exposed, the specimen was fastened to the shaft of a supporting frame. A pair of electrodes for artificial electrical driving was situated near the S-A node. Driving frequency was kept constant about $120 / \mathrm{min}$ throughout each experiment.

The following 4 curves were simultaneously recorded: (i) An A-V nodal transmembrane action potential recorded with a microelectrode inserted in a fixed point throughout drug administration; (ii) A differential curve of this A-V nodal transmembrane action potential; (iii) An atrial electrogram recorded from the region along crista terminalis above the coronary sinus by means of a contiguous bipolar lead; (iv) A ventricular electrogram recorded from the apical region on the right ventricular surface by means of a contiguous bipolar lead.

The following 4 features of the A-V nodal transmembrane action potential were obtained from the recordings on paper: (i) The amplitude of transmembrane action potential; (ii) The maximum rate of rise calculated from the maximum slope in the upstroke of transmembrane action potential; (iii) The rise time, i.e., the duration from the onset to the peak of the upstroke; (iv) The $80 \%$ repolarization time, i.e., the duration from the peak of the upstroke to the point of 80 per cent level of repolarization. 


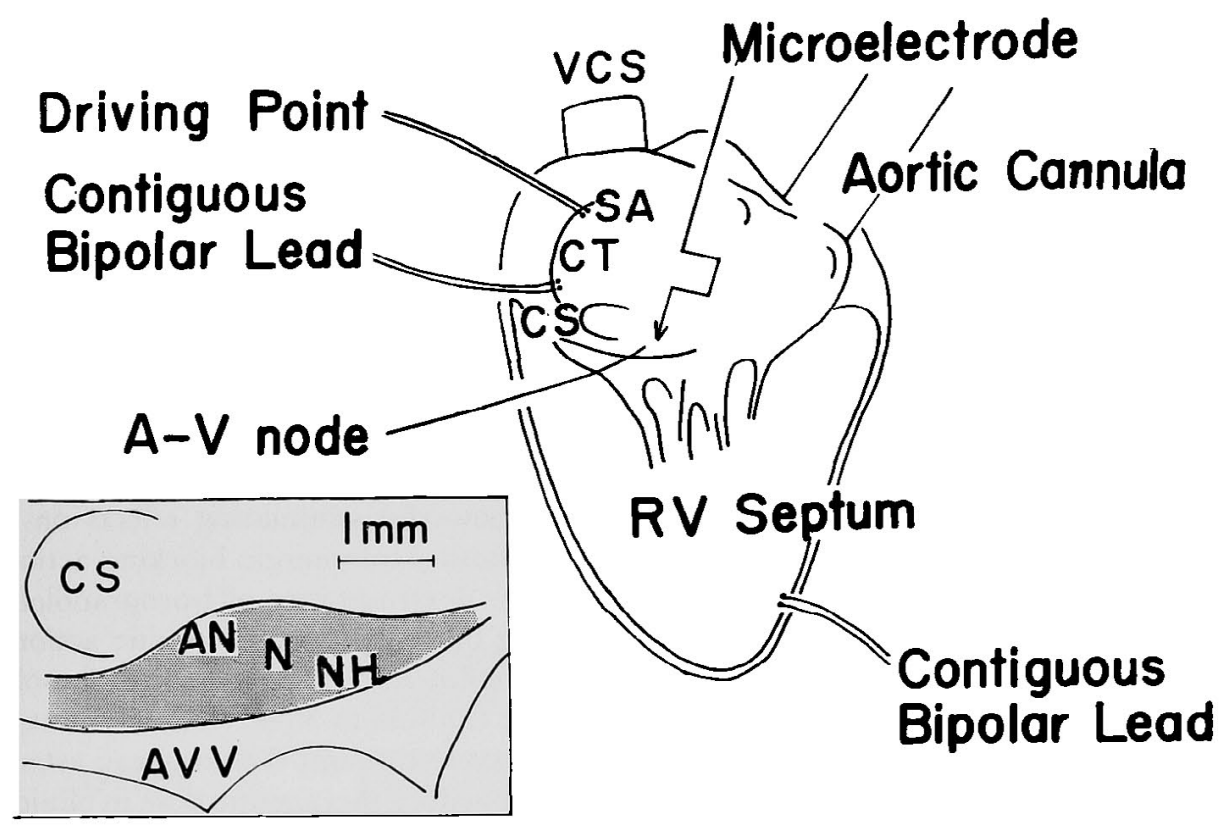

Fig. 1. The septal surface of the right atrium and the right ventricle of the isolated rabbit heart under perfusion in Langendorff's technique. The location of electrodes used for driving the specimen and recording the potentials are schematically indicated. A schema describing the details of the A-V node is inserted at the lower left corner. VCS: superior vena cava, SA: sinoatrial node, GT: crista terminalis, CS : coronary sinus, AN : atrial margin of the A-V node, $\mathrm{N}$ : middle layer of the A-V node, $\mathrm{NH}$ : $\mathrm{His}$ bundle margin of the A-V node, AVV: atrioventricular valve.

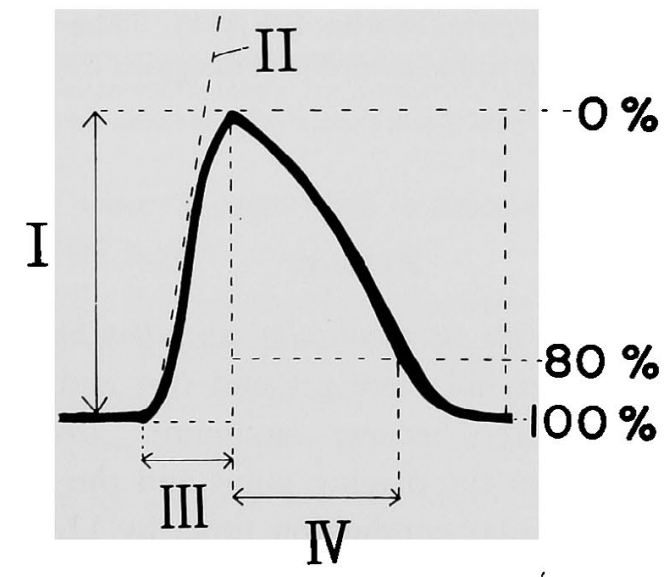

Fig. 2. Parameters representing the contour of the $A-V$ nodal transmembrane action potential. I: amplitude of transmembrane action potential, II : maximum rate of rise (maximum slope of rise), III : rise time, IV: $80 \%$ repolarization time. 
The conduction time to the atrium, the $A-V$ node and the ventricle was expressed with respect to the instant of driving. In deciding the conduction time, the peak in each of the atrial electrogram, the differential curve of the A-V nodal transmembrane action potential and the venticular electrogram was regarded as the arrival point of impulse.

The region where a microelectrode was inserted was classified into 3 layers, i.e., $\mathrm{N}$ (middle layer of the A-V node), AN (atrial margin of the A-V node) and NH (His bundle margin of the A-V node) following Paes de Carvalho et al. ${ }^{3)}$ Accordingly, identification of each layer was made by means of the conduction time of impulse beginning from the instant of driving, the characteristic features of the $A-V$ nodal transmembrane action potential and the anatomical location of the microelectrode.

The following 3 drugs were used in experiments : l-isoproterenol hydrochloride, the popular name isoproterenol, which exerts powerful stimulating effects on $\beta$ adrenergic receptors; dl-propranolol, which has both $\beta$-adrenergic blocking actions and non-specific actions; and d-propranolol, the dextro-isomer of l-propranolol, ${ }^{4}$ which has almost no $\beta$-adrenergic blocking actions but only has non-specific actions. Twenty $\mu \mathrm{g}$ of isoproterenol, $50 \mu \mathrm{g}$ of dl-propranolol and $50 \mu \mathrm{g}$ of d-propranolol were administered respectively through the aortic cannula in $30 \mathrm{sec}$. Since most of the administered drug flowed out after only one cycle through the coronary artery, it was difficult to compare the experimental dosage with a therapeutic dose in clinical use. In preliminary experiments, it had been clarified that the dose of each drug used in the present experiment was equal to several times that which produced a detectable change.

The electrodes used for contiguous bipolar lead and artificial electrical driving of the specimen were made of fine silver wire, and the interpolar distance was $1 \mathrm{~mm}$.

The transmembrane action potential was amplified through a preamplifier (Nihon Koden Co, MZ-3B) and a D-C amplifier (Yokogawa Electric Works, Type3125 ). The differential curve of the $\mathrm{A}-\mathrm{V}$ nodal transmembrane action potential was recorded through a resistance-capacitance differentiator with a time constant of 2 msec. Contiguous bipolar electrograms were amplified through a biophysical ME amplifier (Yokogawa Electric Works, BE-A11). The 4 curves were simultaneously recorded by a photographic recorder (Yokogawa Electric Works, EMO-62) at a paper speed of $10 \mathrm{~cm} / \mathrm{sec}$.

\section{RESULTS}

\section{Effects of isoproterenol on the atrioventricular conduction time}

The effects of isoproterenol were assessed one and a half minute after administration when the effects became maximum. Isoproterenol shortened the conduction time between the driving point and the ventricle, which was regarded as the atrioventricular conduction time, by $17.0 \pm 4.7 \%$ (mean and standard deviation; $\mathrm{n}=11$ ).

Although it was difficult to record the A-V nodal transmembrane action potential keeping a microelectrode inserted in a fixed point throughout drug administration, in 11 cases the effects of isoproterenol were registered success- 

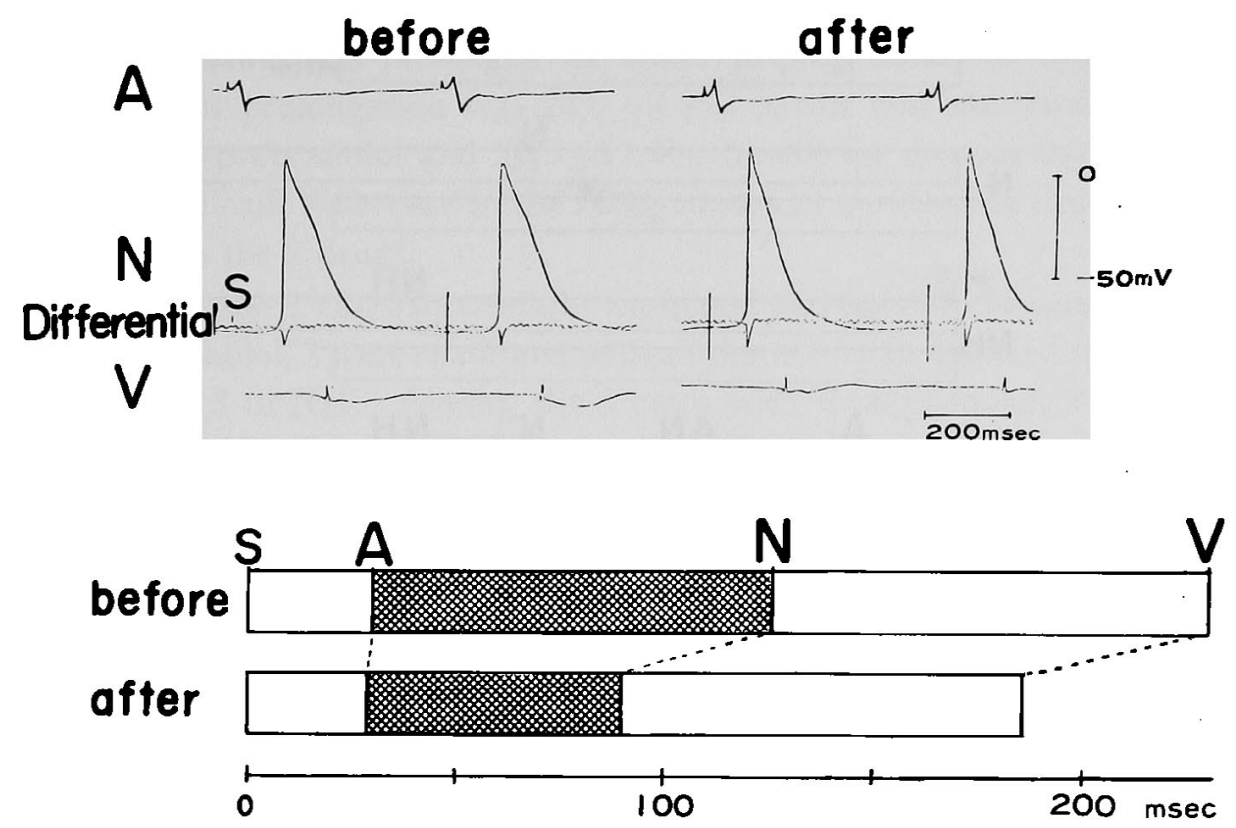

Fig. 3. An experimental case showing effects of isoproternol on the conduction time. Upper part: Transmembrane action potential from $\mathbf{N}$ layer (N) is shown along with contiguous bipolar electrograms from the right atrium (A) and the right ventricle (V). The differential curve of this transmembrane action potential (Differential) is also recorcded in order to decide the arrival point of impulse. The heart rate was kept constant by means of an electrical driving stimulus (S) situated near the S-A node. Lower part: The graph represents the S-atrium, the atrium- $\mathrm{N}$ and the $\mathrm{N}$-ventricle intervals before and after administration of isoproterenol in this case. Each of the peaks in the differential curve and the contiguous bipolar electrograms from the right atrium and ventricle was regarded as the arrival point of impulse. It is clearly shown that isoproterenol shortened the S-ventricle interval, and this shortening occurred mostly between the right atrium and $\mathrm{N}$ layer.

fully. Among them were 3 cases with a microelectrode inserted in AN, 4 cases in $\mathrm{N}$, and 4 in $\mathrm{NH}$ layer.

In order to identify the region where the atrioventricular conduction time is markedly shortened by isoproterenol, one typical case with a microelectrode inserted in $\mathbf{N}$ was sampled as illustrated in Fig. 3. In this case, the stimulusatrium interval was little changed $(30 \rightarrow 29 \mathrm{msec})$. However, the atrium-N interval was shortened by $35 \mathrm{msec}(96 \rightarrow 61 \mathrm{msec})$, and the $\mathrm{N}$-ventricle interval was shortened by $8 \mathrm{msec}(104 \rightarrow 96 \mathrm{msec})$. That is, about 80 per cent of the total shortening of the atrioventricular conduction time occurred in the atrium$\mathrm{N}$ interval.

Almost similar findings were detected in the other 3 cases with a microelectrode inserted in $\mathbf{N}$ layer. 


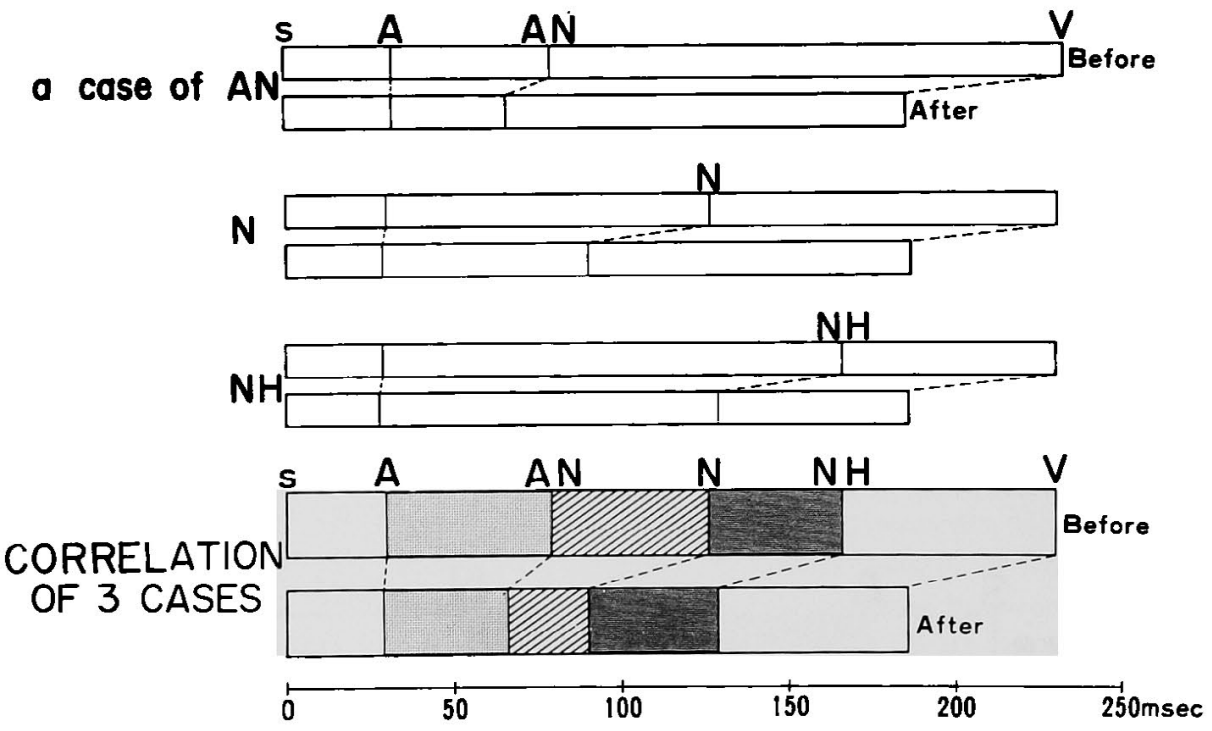

Fig. 4. A detailed representation of effects of isoproterenol on the conduction time. Upper part: Changes in the conduction time are shown with each of the 3 experimental cases of $\mathrm{AN}, \mathrm{N}$, and $\mathrm{NH}$ where a microelectrode was inserted. $S$ : site of driving stimulus near the S-A node, A: the right atrium, $\mathrm{V}$ : the right ventricle. Lower part: Findings in these 3 cases were schematically correlated into one figure. As a result of the correlation, it became evident that the most marked shortening took place between $A N$ and $N$ layer and the next one took place between the right atrium and AN layer.

In the next stage, a more detailed analysis was made with the $\mathrm{A}-\mathrm{V}$ nodal pathway divided into 4 , i.e., the atrium-N, the $\mathrm{AN}-\mathrm{N}$, the $\mathrm{N}-\mathrm{NH}$, and the NH-ventricle intervals. Since no experiment was conducted with microelectrodes inserted in the 3 layers (AN, N, NH) simultaneously, the outcomes of 3 experiments with a microelectrode inserted in one of the 3 layers respectively were schematically correlated (Fig. 4). Correlation of the 3 representative cases demonstrated the interval shortening to be as follows: stimulus-atrium, $1 \mathrm{msec}(30 \rightarrow 29 \mathrm{msec})$; atrium-AN, $12 \mathrm{msec}(49 \rightarrow 37 \mathrm{msec}) ; A N-N, 23 \mathrm{msec}$ $(47 \rightarrow 24 \mathrm{msec}) ; \mathrm{N}-\mathrm{NH}, 1 \mathrm{msec}(40 \rightarrow 39 \mathrm{msec}) ;$ and NH-ventricle, $7 \mathrm{msec}$ (64 $\rightarrow 57 \mathrm{msec}$ ) (Fig. 4). Thus, the most notable shortening of the conduction time induced by isoproterenol took place between $\mathrm{AN}$ and $\mathrm{N}$ layer, the next one being between the atrium and AN layer. In these 3 cases, the atrioventricular conduction time before administration of isoproterenol was almost the same and the shortening of the atrioventricular conduction time due to isoproterenol was also almost the same. The results of the 3 cases were thus easily juxtaposed to produce a schematic figure.

Effects of dl-propranolol and d-propranolol on the $A$-V transmission

The effects of drugs were assessed at the time of maximal effect, that is, 
one and a half minute after administration. The conduction time between the driving point and the ventricle, which was regarded as the atrioventricular conduction time, was prolonged by either dl-propranolol or d-propranolol. The per cent prolongation was $28.0 \pm 9.5 \%$ (mean and standard deviation; $\mathrm{n}=7)$ for dl-propranolol and $26.5 \pm 11.4 \%(\mathrm{n}=6)$ for d-propranolol. There was no significant difference in the atrioventricular conduction time prolongation between the 2 drugs.

Among the 7 cases successfully examined throughout the administration of dl-propranolol, 2 were examined with a microelectrode inserted in AN layer, 2 in $\mathrm{N}$, and 3 in NH. Among the 6 cases with d-propranolol, 2 cases were examined in $\mathrm{AN}, \mathrm{N}$, and $\mathrm{NH}$ layer respectively.

In order to identify the region where the atrioventricular conduction time is prolonged by dl- and d-propranolol, 2 typical cases (a dl-propranolol and a d-propranolol experiment) which were conducted with a microelectrode inserted in $\mathrm{N}$ layer were sampled as illustrated in Figs. 5 and 7 . In the dlpropranolol experiment, the stimulus-atrium interval was not changed $(30 \rightarrow$ $30 \mathrm{msec})$. However the atrium-N interval was prolonged by $28 \mathrm{msec}(80 \rightarrow$ $108 \mathrm{msec})$ and the $\mathrm{N}$-ventricle interval was prolonged by $15 \mathrm{msec}(66 \rightarrow 81 \mathrm{msec})$ (Fig. 5). In the d-propranolol experiment, the stimulus-atrium interval was little changed $(39 \rightarrow 40 \mathrm{msec})$. However, the atrium-N interval was prolonged by $32 \mathrm{msec}(91 \rightarrow 123 \mathrm{msec})$ and the $\mathrm{N}$-ventricle interval was prolonged by
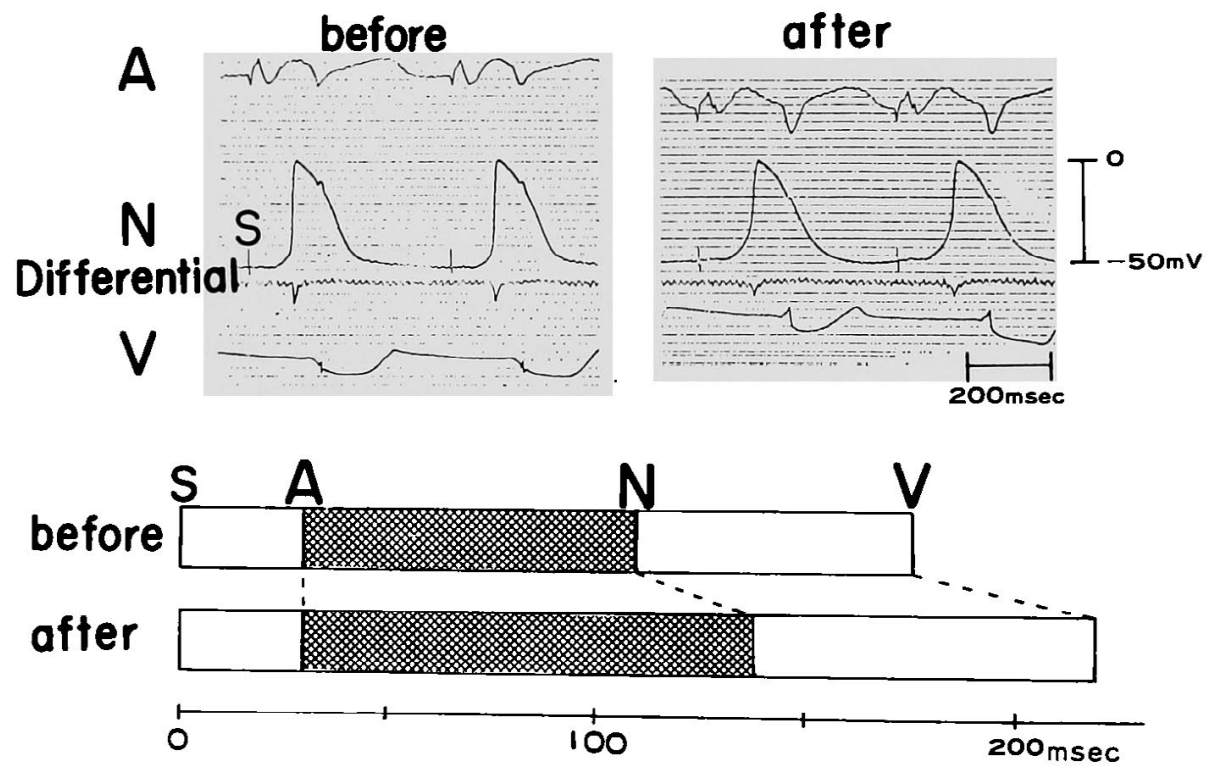

Fig. 5. An experimental case showing effects of dl-propranolol on the conduction time. Legends for the upper and lower part are the same as those in Fig. 3. dl-propranolol prolonged both of the atrium-N and the N-ventricle intervals. 

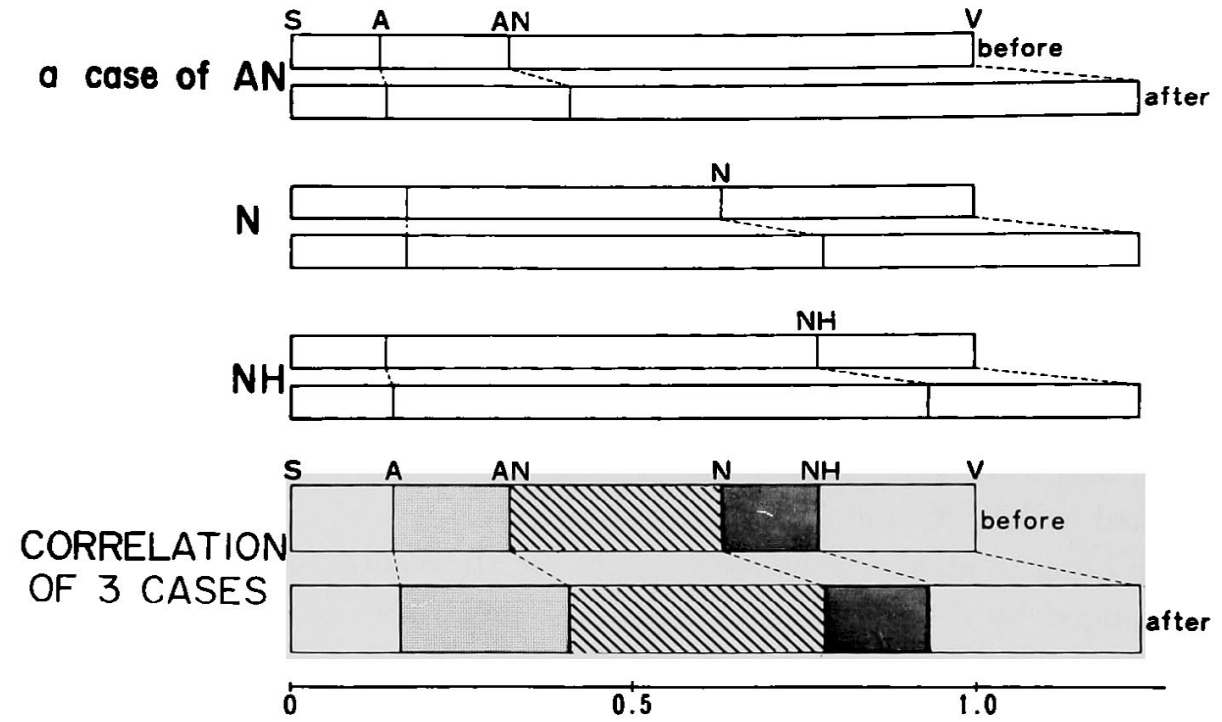

Fig. 6. A detailed representation of effects of dl-propranolol on the conduction time. Legends for the upper and lower part are the same as those in Fig. 4. Since the stimulus-ventricle intervals of these 3 cases before drug administration differed, they were all normalized to the value of 1.0. As a result of the correlation, it became evident that dl-propranolol prolonged the atrium-AN, the AN-N, and the NH-ventricle intervals.
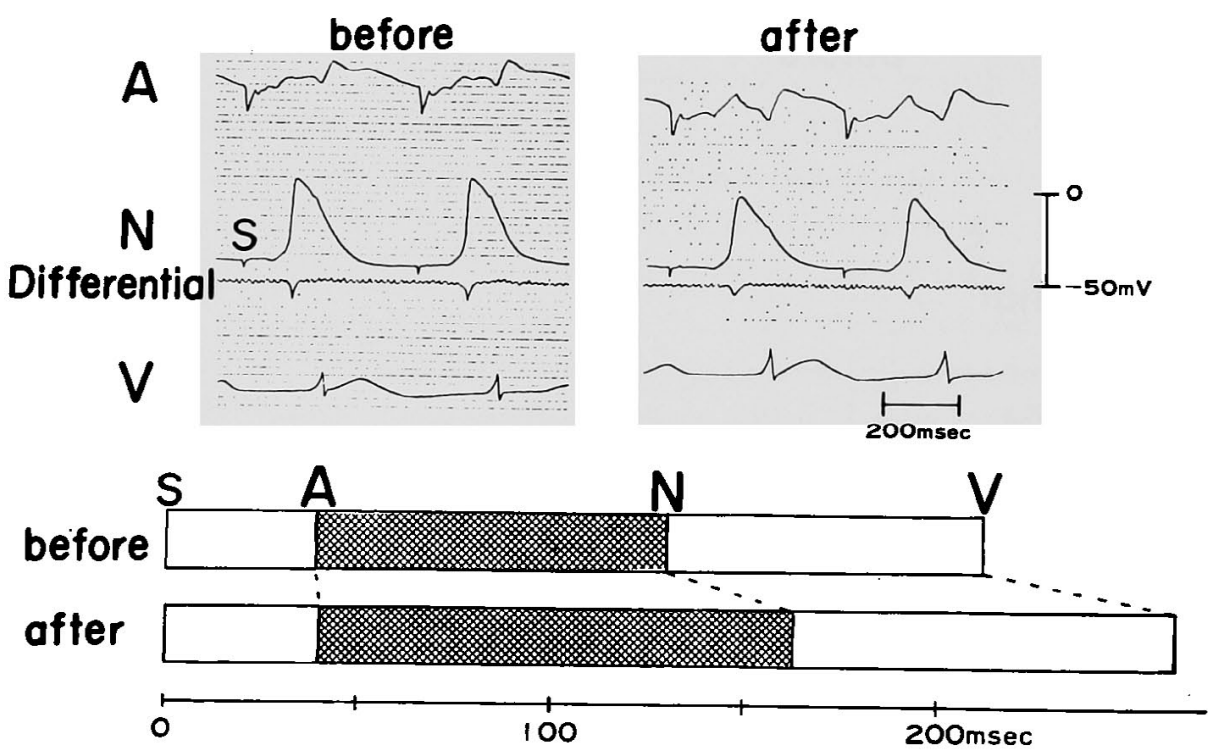

Fig. 7. An experimental case showing effects of d-propranolol on the conduction time. Legends for the upper and lower part were the same as those in Fig. 3. d-Propranolol prolonged both of the atrium-N and $\mathrm{N}$-ventricle intervals. 

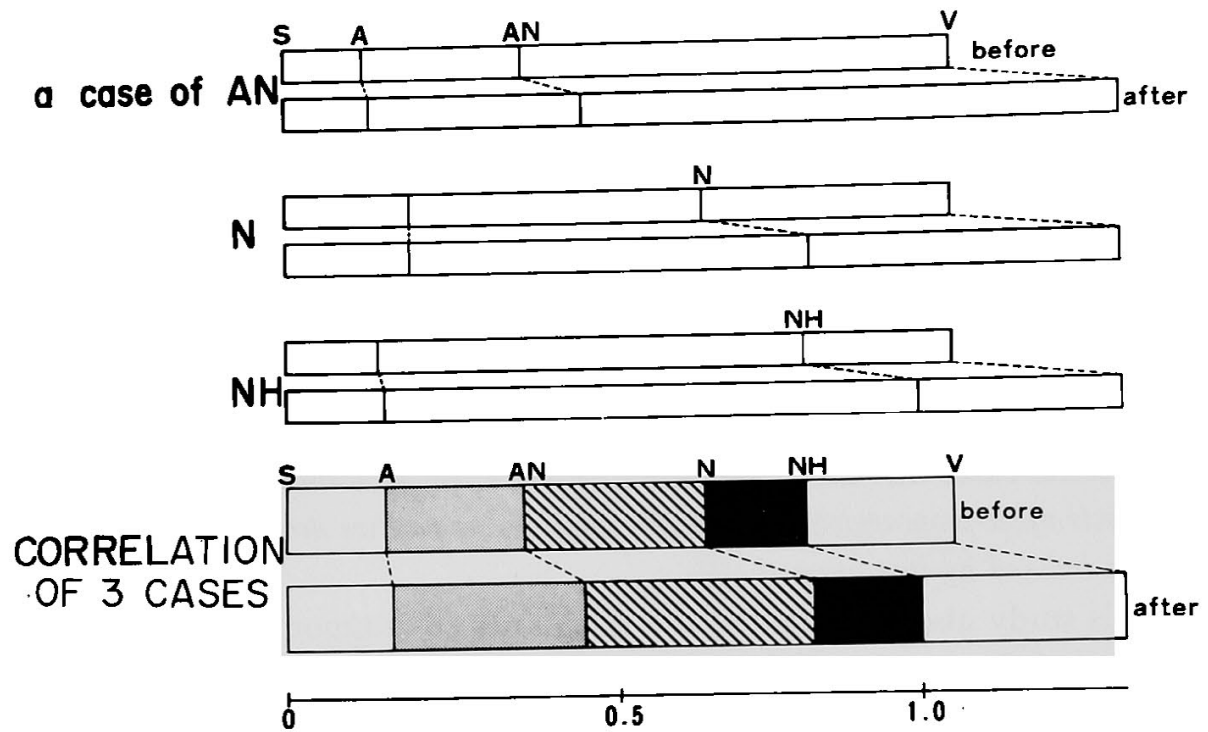

Fig. 8. A detailed representation of effects of d-propranolol on the conduction time. Legends for the upper and lower part are the same as those in Fig. 4. Since the stimulus-ventricle intervals of these 3 cases before drug administration differed, they were all normalized to the value of 1.0. As a result of the correlation, it became evident that d-propranolol prolonged the atrium-AN, the $\mathrm{AN}-\mathrm{N}$, and the $\mathrm{NH}$-ventricle intervals.

$17 \mathrm{msec}(82 \rightarrow 99 \mathrm{msec}$ ) (Fig. 7). That is, both drugs markedly prolonged the atrium- $\mathrm{N}$ interval and the $\mathrm{N}$-ventricle interval but the stimulus-atrium interval remained almost unchanged.

In the next stage, a more detailed analysis was made with $\mathrm{A}-\mathrm{V}$ nodal pathway divided into 4, i.e., the atrium-AN, the $\mathrm{AN}-\mathrm{N}$, the $\mathrm{N}-\mathrm{NH}$, and the $\mathrm{NH}$-ventricle intervals. The outcomes of the 3 experiments ( $\mathrm{AN}, \mathrm{N}, \mathrm{NH}$ ) each with a microelectrode inserted in one of the 3 layers were schematically correlated (Figs. 6 and 8). Because the stimulus-ventricle intervals of these 3 cases before drug administration each differed, they were all normalized to the value of 1.0 in the illustration so that comparison could be made easier. In Figs. 6 and 8, it is seen that both dl- and d-propranolol prolonged the atrium-AN, the $\mathrm{AN}-\mathrm{N}$, and the $\mathrm{NH}$-ventricle intervals, and hardly prolonged the stimulus-atrium and the N-NH intervals.

The second degree A-V block was induced by single or repeated administration of either dl- or d-propranolol. When observed at AN layer where a microelectrode was inserted, the second degree A-V block occurred distal to AN layer in all 3 cases (2 dl-propranolol and one d-propranolol). When observed at the $\mathrm{N}$ layer where a microelectrode was inserted, it occurred proximal to $\mathrm{N}$ layer in all 4 cases (2 experiments with each drug). Besides these experiments, in 2 cases, i.e., a dl-propranolol and a d-propranolol 
experiment, a microelectrode was inserted in AN layer at first. About $10 \mathrm{sec}$ later this microelectrode was resituated in $\mathrm{N}$ layer. It was observed that with an impulse failing to reach the ventricle, the conduction was complete up to AN layer, but did not attain $\mathrm{N}$ layer, leaving only a slight deflection (Fig. 9). On the basis of these findings, it could be concluded that the second degree A-V block induced by either dl- or d-propranolol occurred between $\mathrm{AN}$ and $\mathrm{N}$ layer.

In addition, the second degree A-V block induced by each drug always began with the Wenckebach phenomenon. After the Wenckebach phenomenon, some cases advanced toward 2:1, 3:1, or 4:1 block.

Effects of dl-propranolol and d-propranolol on the positive dromotropic action in the $A-V$ node induced by isoproterenol

This study also investigated the possibility of antagonizing effects of different intensity upon the positive dromotropic action induced by isoproterenol
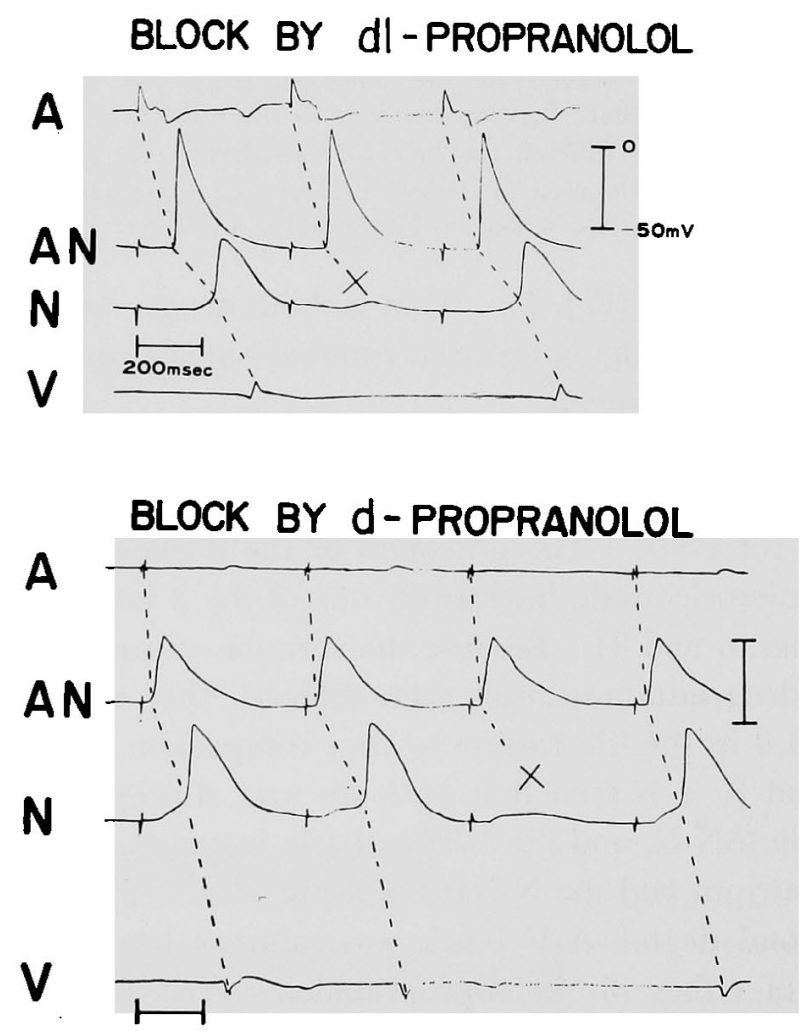

Fig. 9. Experimental case showing the second degree A-V block induced by dl- and d-propranolol respectively. In recording transmembrane action potentials, a microelectrode was insterted into AN layer at first, soon after it was resituated to $\mathrm{N}$ layer. The transmembrane action potentials in $\mathrm{AN}$ and $\mathrm{N}$ layer are shown here as if recorded simultaneously. It is evident that the second degree $\mathrm{A}-\mathrm{V}$ block occurred between $\mathrm{AN}$ and $\mathrm{N}$ layer by each drug. 


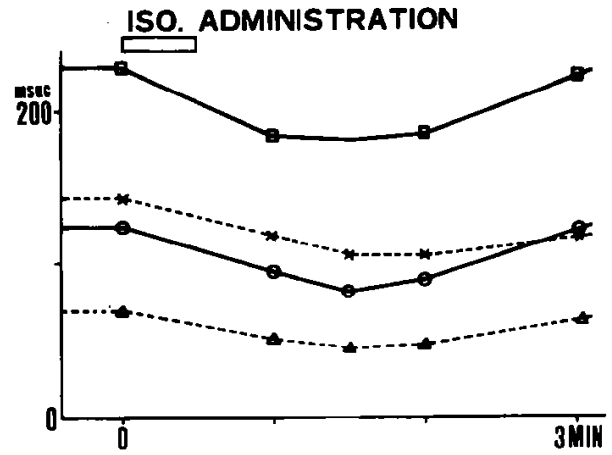

๑ STIMULUS-VENTRICLE INTERYAL

0 " -Nor NH " $\times-\cdots \times 80 \%$ REPOLARIZATION TIME $\triangle \cdots \Delta$ RISE TIME
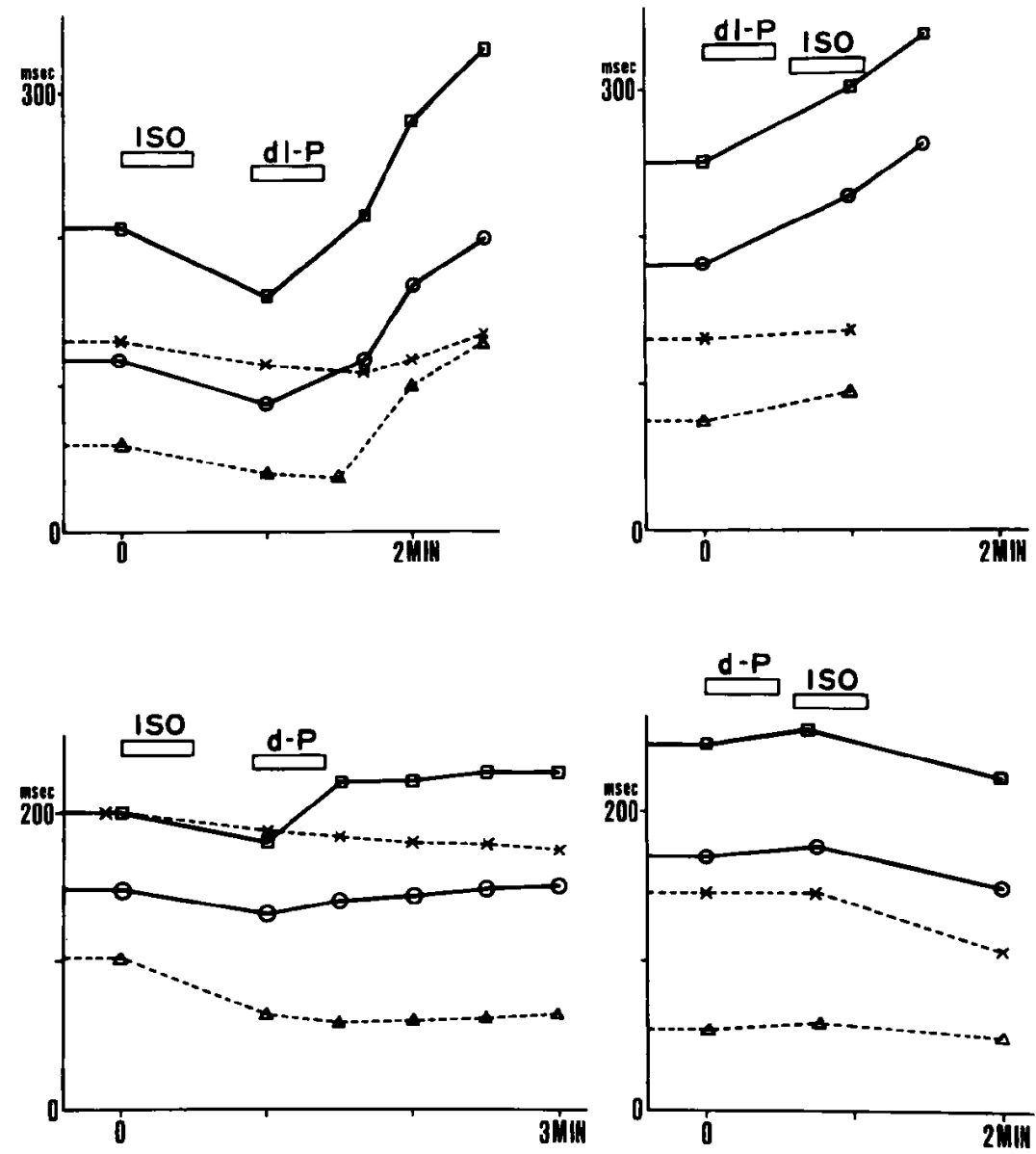

Fig. 10. Effects of dl- and d-propranolol on the dromotropic action of isoproterenol. Each of the 5 panels corresponds to each of the 5 different experimental cases. ISO: isoproterenol, dl-P: dl-propranolol, d-P: d-propranolol. As is evident from these cases, dl-propranolol antagonized the positive dromotropic action of isoproterenol but d-propranolol did not.

Changes in the rise time corresponded to those in conduction time. However, changes in the $80 \%$ repolarization time did not always so correspond as seen in the lower left panel. 
from administration of either dl-or d-propranolol. For this purpose, 2 types of experiment were conducted. First, dl- or d-propranolol was administered $30 \mathrm{sec}$ after treatment with isoproterenol. Second, they were administered $30 \mathrm{sec}$ before the same treatment. Two or 3 cases were examined in each of the 4 drug combinations. In every case, the pre- or post-treatment of dl-propranolol antagonized the shortening of the atrioventricular conduction time induced by isoproterenol. On the other hand, the pre- or post-treatment of d-propranolol did not antagonize it. Typical cases from 4 groups are shown in Fig. 10.

In addition, changes in the rise time always corresponded to those in the atrioventricular conduction time, while changes in the $80 \%$ repolarization time did not always so correspond.

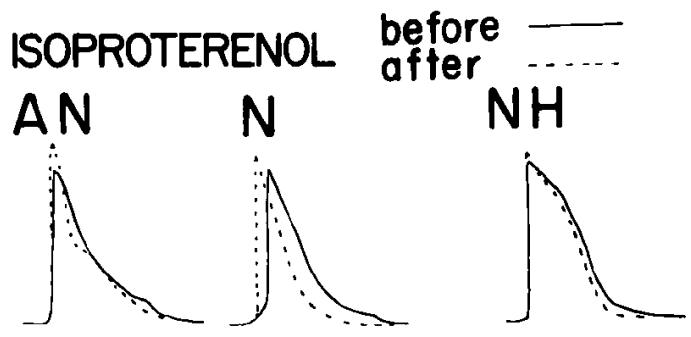

\section{dl -PROPRANOLOL}
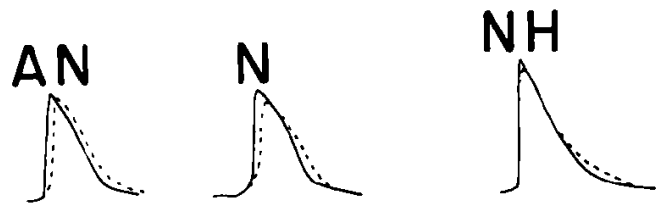

d-PROPRANOLOL
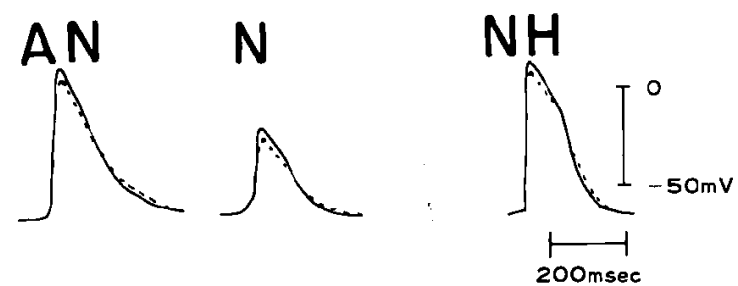

Fig. 11. Typical cases showing effects of isoproterenol, dl- and d- propranolol on the transmembrane action potential from AN, N, and NH layer. Isoproterenol sharpened the contour of transmembrane action potential from every layer of the A-V node, while dl-and d-proranolol dulled it. Changes in the transmembrane action potential appear to be more accentuated in AN and $\mathrm{N}$ layer rather than in $\mathrm{NH}$ layer, and by dl-propranolol more than by $\mathrm{d}-$ propranolol. 

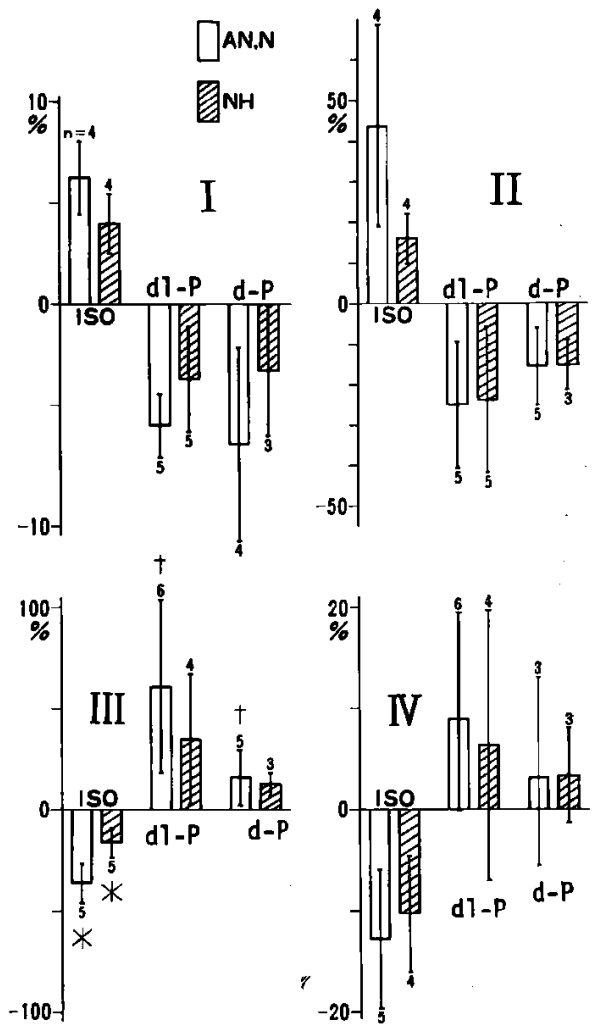

Fig. 12. Changes in the $\mathrm{A}-\mathrm{V}$ nodal transmembrane action potential induced by isoproterenol, dl- and d-propranolol. A-V nodal transmembrane action potentials were classified into 2 groups, i.e., a group formed of AN and $\mathrm{N}$ layer combined and that of $\mathrm{NH}$ layer. Isoproterenol (ISO) increased amplitude of transmembrane action potential (I) and maximum rate of rise (II), and decreased rise time (III) and $80 \%$ repolarization time (IV). Changes induced by dl-propranolol (dl-P) and d-propranolol (d-P) were opposite to those by isoproterenol. Changes in these features tended to be more marked in the group of $\mathrm{AN}$ and $\mathrm{N}$ layer rather than in the $\mathrm{NH}$ layer group, and more by dl-propranolol than by d-propranolol. There were significant differences $(\mathrm{P}<$ 0.05 ) between $*$ and $*$, and between + and + .

Effects of isoproterenol, dl-propranolol and d-propranolol on the $A-V$ nodal transmembrane action potential

As shown in Fig. 11, the contour of the A-V nodal transmembrane action potentials was sharpened by isoproterenol, but dulled by dl- and d-propranolol. In addition, the changes appear to be more marked in $\mathrm{AN}$ and $\mathrm{N}$ layer than NH layer, and dl-propranolol appears to produce a sharper variation than d-propranolol.

Per cent changes in 4 features of the transmembrane action potential were compared between the 2 groups, i.e., a group formed of $\mathrm{AN}$ and $\mathrm{N}$ layer 


\section{SLOW DEPOLARIZATION}

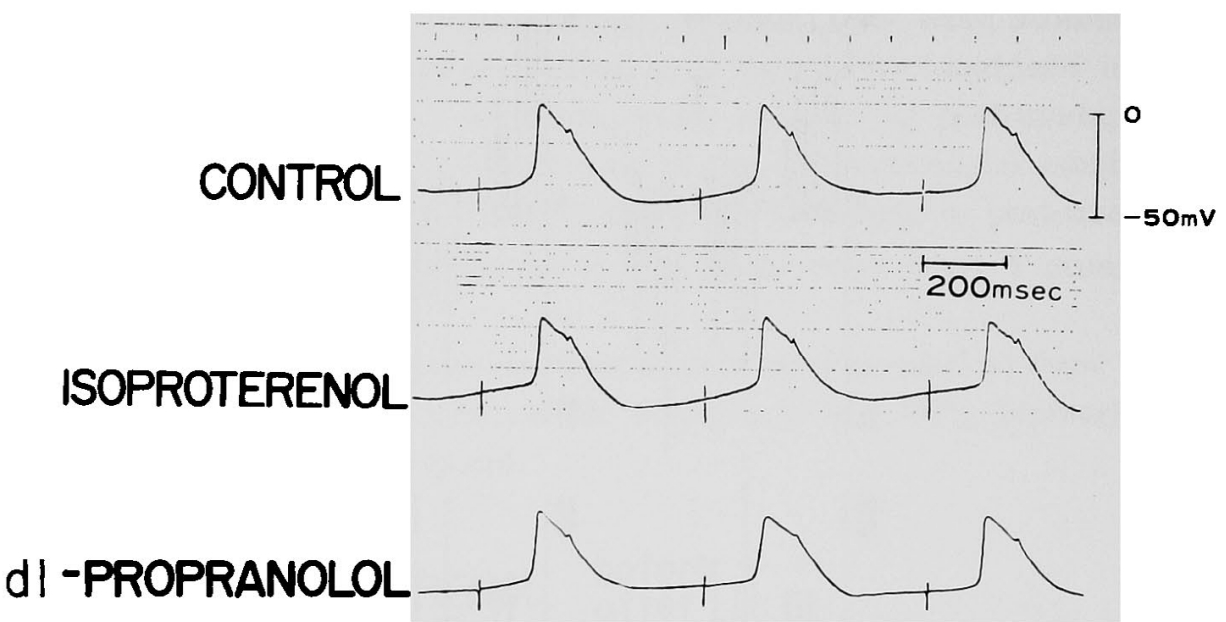

Fig. 13. An experimental case showing effects of isoproterenol and dlpropranolol on slow diastolic depolarization of the A-V nodal transmembrane action potential. Isoproterenol increased the slope of slow diastolic depolarization but dl-propranolol decreased it.

combined, and a NH layer group (Fig. 12). In both groups, isoproterenol increased the amplitude of transmembrane action potential and the maximum rate of rise, and decreased the rise time and the $80 \%$ repolarization time. However, dl- and d-propranolol, decreased the amplitude of transmembrane action potential and the maximum rate of rise, and increased the rise time. The $80 \%$ repolarization time was increased by dl-propranolol, and only tended to be increased by d-propranolol.

Changes of these features were more accentuated in $\mathrm{AN}$ and $\mathrm{N}$ than $\mathrm{NH}$ layer group, and dl-propranolol produced more marked changes than d-propranolol. But significant differences were recognized only on the following points: per cent decrease in rise time induced by isoproterenol with $A N$ and $N$ as compared to $\mathrm{NH}$ layer group; and per cent increase in rise time induced by dl-propranolol as compared to d-propranolol.

The transmembrane action potentials from about $200 \mathrm{~A}-\mathrm{V}$ nodal single fibers were recorded in the present experiment using 61 rabbit hearts. However only one slow diastolic depolarization was recognized in $\mathrm{NH}$ layer. Its slope was increased from $0.031 \mathrm{mV} / \mathrm{msec}$ to $0.046 \mathrm{mV} / \mathrm{msec}$ by administration of isoproterenol, and thereafter this increased slope was decreased to 0.024 $\mathrm{mV} / \mathrm{msec}$ by administration of dl-propranolol (Fig. 13). 


\section{Discussion}

1. The relationship between the $A-V$ transmission and $\beta$-adrenergic receptors

Studies using the technique of His bundle electrogram have demonstrated that a shortening of the atrioventricular conduction time induced by isoproterenol took place between the atrium and His bundle in conscious dogs (Wallace et $\mathrm{al}^{51}$ ) and in human cases as well (Damato et $\left.\mathrm{al}^{6}\right)$. However, the reliability of interpretation obtained from His bundle electrogram may not be satisfactory, nor is it detailed enough to show the particular region within the A-V node which is most responsible for the positive dromotropic action of isoproterenol. The present study, in which transmembrane action potentials were recorded from the $\mathrm{A}-\mathrm{V}$ node of isolated rabbit hearts, would substantiate the results obtained from His bundle electrogram. In addition, it was demonstrated that the most marked shortening of conduction time induced by isoproterenol took place between $\mathrm{AN}$ and $\mathrm{N}$ layer and the second most notable one between the atrium and AN layer. Because AN layer is the atrial margin of the A-V node and $\mathrm{N}$ layer is its middle layer, the region between the atrium and $\mathrm{AN}$ layer, and the region between $\mathrm{AN}$ and $\mathrm{N}$ layer can be both considered as the anterior half of the A-V node. Therefore, it can be stated that a shortening of the atrioventricular conduction time induced by isoproterenol takes place in the anterior half of the $\mathrm{A}-\mathrm{V}$ node.

Isoproterenol-induced positive dromotropic action described above was not antagonized by d-propranolol which lacks in $\beta$-adrenergic blocking actions, but, rather, markedly so by dl-propranolol which does have $\beta$-adrenergic blocking actions.

From a pharmacological point of view, effects of isoproterenol on cardiac function can be regarded as stimulating actions on $\beta$-adrenergic receptors. Besides, the positive dromotropic action of isoproterenol was antagonized by specific $\beta$-adrenergic blocking mechanisms of dl-propranolol. Therefore, the results of the present study suggest that $\beta$-adrenergic receptors mediate the dromotropic action mostly in the anterior half of the $A-V$ node.

Because the A-V node has been shown to have a number of catecholaminecontaining neurones, ${ }^{2)}$ it can be anticipated that the $\mathrm{A}-\mathrm{V}$ nodal function is closely related to $\beta$-adrenergic receptors. This presumption was electrophysiologically and pharmacologically, that is, functionally, supported by the present study. In addition, it is suggested that mode of distribution of sympathetic-nerve endings in the anterior half of the A-V node may differ from that in the posterior half. 
2. Negative dromotropic action of $\beta$-adrenergic blocking agents as possibly due to $\beta$-adrenergic blocking mechanisms or non-specific mechanisms

Whitsitt and Lucchesi' ${ }^{\text {? }}$ have reported that the atrioventricular conduction time is prolonged by dl-propranolol and hardly prolonged by d-propranolol at the same dose level. Their results are not consistent with the present findings in the isolated rabbit heart, namely, that both dl-propranolol and dpropranolol produce similar prolongations of the atrioventricular conduction time. In addition, Damato et al, ${ }^{8)}$ who recorded His bundle electrogram in human subjects, have reported that dl-propranolol prolonged the conduction time through the $\mathrm{A}-\mathrm{V}$ node without any effect on the His bundle-ventricle interval, i.e., the ventricular conduction system. In the present study, however, dl-propranolol prolonged not only the conduction time through the A-V node but also the $\mathrm{NH}$-ventricle interval, which can be regarded as the ventricular conduction system because the NH layer is close to His bundle.

The reason why the results of the present investigation on the isolated heart are not consistent with the observations on the in situ heart may be that catecholamines are insufficient in the isolated heart. It may be considered that because of catecholamine insufficiency, the isolated heart is mainly affected by non-specific mechanisms of dl- and d-propranolol, but little afffected by specific $\beta$-adrenergic blocking mechanisms of dl-propranolol. This consideration was supported by the result that the positive dromotropic action induced by isoproterenol administration on the anterior half of the $A-V$ node was antagonized by $\mathrm{dl}$-propranolol which has $\beta$-adrenergic blocking actions but not by d-propranolol which lacks in them.

From the facts described above, it can be concluded that in the in situ heart or in the sympathomimetic amine excess (isoproterenol administration) heart, $\beta$-adrenergic blocking mechanisms are mainly responsible for the negative dromotropic action of dl-propranolol and it occurs in the anterior half of the A-V node. On the other hand, in the isolated heart where catecholamines are insufficient, non-specific mechanisms are mainly responsible for such action which occurs not only in the anterior half of the A-V node but also between $\mathrm{NH}$ and the ventricle, i.e., in the ventricular conduction system.

\section{The mode of the second degree $A-V$ block induced by dl-propranolol and d-propranolol}

The second degree A-V block induced by $\mathrm{dl}$ - and d-propranolol took place between $\mathrm{AN}$ and $\mathrm{N}$ layer. This region is almost the same as the part where the block of transmission was induced by acetylcholine, high rate, anoxia or a combination of these factors. ${ }^{9}$, 10) In the present study using dl- and dpropranolol, there was no block of transmission proximal to the region between 
$\mathrm{AN}$ and $\mathrm{N}$ layer, that is, in the region between the atrium and $\mathrm{AN}$ layer where the marked prolongation of the conduction time had already occurred. It is of interest whether this finding is due to a functional property, i.e., the decremental conduction, or due to structural characteristics of the region between $\mathrm{AN}$ and $\mathrm{N}$ layer.

The second degree A-V block induced by dl- and d-propranolol always began with the Wenckebach phenomenon. This is in agreement with the widely believed finding that the $A-V$ block within the $A-V$ node under various conditions is apt to show the Wenckebach phenomenon.

4. Effects of isoproterenol, dl-propranolol and d-propranolol on the $A-V$ nodal transmembrane action potential, and their relationship to the $A-V$ transmission

Isoproterenol increased the amplitude of transmembrane action potential and the maximum rate of rise, and decreased the rise time. The effects of dland d-propranolol were opposite to those of isoproterenol. Because it can be considered that a velocity of conduction is dependent on the depolarization phase of transmembrane action potential, the changes in the transmembrane action potential described above support the positive dromotropic action of isoproterenol and the negative dromotropic actions of dl- and d-propranolol.

Changes in the A-V nodal transmembrane action potential induced by these drugs tended to be more in evidence in $\mathrm{AN}$ and $\mathbf{N}$ layer than in NH layer. This tendency corresponded to the finding that changes in the atrioventricular conduction time were more marked in $\mathrm{AN}$ and $\mathrm{N}$ layer than in $\mathrm{NH}$ layer.

On the other hand, the tendency for changes in the A-V nodal transmembrane action potential to be more marked with dl-propranolol than with d-propranolol did not correspond to the finding that both dl- and d-propranolol equally prolonged the atrioventricular conduction time. There are no sufficient data explaining this apparent contradiction. The $80 \%$ repolarization time was decreased by isoproterenol but increased by dl-propranolol. These findings seem to indicate that $\mathrm{A}-\mathrm{V}$ nodal refractory periods are shortened by isoproterenol ${ }^{11)}$ and prolonged by dl-propranolol. ${ }^{7), 8), 11)}$ However, changes in the $80 \%$ repolarization time did not always correspond to those in the conduction time as shown in Fig. 10.

There are many studies about effects of sympathomimetic amines or $\beta$ adrenergic blocking agents on the transmembrane action potential from the atrial muscle, Purkinje fiber and the ventricular muscle. Concerning the A-V node, however, there is only one study of Matsuda et al. ${ }^{12)}$ The latter reported on only one isolated dog heart that adrenaline increased " action potential rising velocity", slightly increased "spike height" and decreased 
"the spike delay" (similar to rise time in the present study). The report of the same authors using adrenaline and this one using isoproterenol basically agree.

Transmembrane action potentials from about 200 points within the A-V node were recorded from 61 rabbit hearts, but only one slow diastolic depolarization was recorded in $\mathrm{NH}$ layer. It is of interest that the $\mathrm{A}-\mathrm{V}$ nodal fiber hardly showed the slow diastolic depolarization, i.e., the pacemaker activity. In this case, isoproterenol increased the slope of slow diastolic depolarization, and dl-propranolol decreased it. These findings are similar to our previous observations $^{13)}$ on the S-A nodal fiber. In addition, it has been reported ${ }^{14)}$ that the slope of the slow diastolic depolarization from Purkinje fibers of sheep hearts was accentuated by isoproterenol. Therefore, it is suggested that the pacemaker activity in the specialized conducting system is increased by isoproterenol and decreased by dl-propranolol.

\section{AGKNOWLEDGEMENTS}

The author sincerely expresses his thanks to Prof. K. Yamada and Asst. Prof. M. Okajima for their interest and guidance in the completion of this study. The author also wishes to thank Dr. K. Hori and Dr. O. Mizutani for their kind advice, and all his colleagues for their generous cooperation.

\section{REFERENGES}

1. Ahlquist RP: Am J Physiol 153: 586,1948

2. Otsuka N, OchiJ: Adv Neurol Sci 13: 803, 1970 (in Japanese)

3. Paes de Carvalho A, de Almeida DF: Circulat Res 8: 801, 1960

4. Howe R, Shanks RG: Nature 210: 1336, 1966

5. Wallace AG, Troyer WG, Lesage MA, Zotti EF: Circulat Res 18: 140, 1966

6. Damato AN, Lau SH, Helfant RH, Stein E, Berkowitz WD, Cohen SI: Circulation 39 : 287, 1969

7. Whitsitt LS, Lucchesi BR: Circulat Res 23: 585, 1968

8. Berkowitz WD, Wit AL, Lau SH, Steiner G, Damato AN: Circulation 40: 855, 1969

9. Hoffman BF, Cranefield PF : Electrophysiology of the heart, McGraw-Hill Inc, New York, 157,1960

10. Yamada K, Okajima M, Hori K, Fujino T, Muraki H, Hishida H, Kobayashi T: Circulat Res 22 : 707, 1968

11. Kabela E, Mendez R: Brit J Pharmacol 26: 473, 1966

12. Matsuda K, Hoshi T, Kameyama S: Tohoku J Exptl Med 68 : 16, 1958

13. Yamada K, Okajima M, Hori K, Kohno M, Tatematsu H, Jen S (Nin S), Nagata Y, Hayashi H, Mizutani O: Ann Rep Environ 22: 117, 1970 (in Japanese)

14. Kassebaum DG, Van Dyke AR: Circulat Res 19 : 940,1966 